\title{
An updated mortality risk analysis of the post-pubertal undescended testis
}

\author{
Ankur Shah, MBA ${ }^{1}$; Paul J. Feustel, $\mathrm{PhD}^{2}$; Jennifer Knuth, $\mathrm{MD}^{3}$; Charles Welliver, $\mathrm{MD}^{1,4}$ \\ ${ }^{1}$ Department of Surgery, Division of Urology, Albany Medical College; ${ }^{2}$ Center for Neuropharmacology and \\ Neuroscience, Albany Medical College; ${ }^{3}$ Department of Anesthesiology, Albany Medical College; ${ }^{4}$ Albany Stratton \\ VA Medical Center; Albany, NY, United States
}

Cite as: Can Urol Assoc J 2018 July 24; Epub ahead of print. http://dx.doi.org/10.5489/cuaj.5296

Published online July 24, 2018

$* * *$

\section{Abstract}

Introduction: The undescended testicle (UDT) presents a problem in post-pubertal (PP) men, as it carries an increased risk of developing a germ cell tumour (GCT). Management of the PP patient with an UDT must weigh the relative risk (RR) of perioperative mortality (POM) from orchiectomy against the lifetime risk of death from a GCT.

Methods: The most recent data on GCT mortality were obtained from the National Centre for Health Statistics. Standard life tables were used to calculate the cumulative risk over a man's lifetime based on age. The increased RR of GCT in men with UDT was determined by weighing the observed and expected rates from literature review. Life table data was then multiplied by the RR to define the risk of GCT in men with UDT. Data from patients undergoing similar risk surgical procedures stratified by American Society of Anesthesiologists (ASA) class was used to determine POM.

Results: Lifetime risk of dying from GCT decreases with increasing age. POM exceeded risks of death from GCT for men after age 50.2 for ASA class 1 and age 35.4 for ASA class 2. Men with an ASA class higher than 2 have a higher risk of POM compared to GCT for all ages.

Conclusions: We found different ages from previous reports at which observation is advised. We consider prophylactic orchiectomy only in men who are under 50.2 years if ASA class 1 and under 35.4 years if ASA class 2. Men with an ASA class 3 or higher should always undergo observation. 


\section{Introduction}

While the potential for future fertility is typically a concern with undescended testicles (UDT) in infants and children, the UDT found in post-pubertal (PP) men will likely have limited fertility potential. ${ }^{1}$ The UDT presents a problem in PP men as it has an ongoing and increased risk of developing a testicular germ cell tumour (GCT). ${ }^{2-4}$

Management of the PP patient first presenting with an UDT must weigh the relative risk (RR) of the lifetime development and mortality from a GCT compared to the perioperative mortality (POM) risk of definitive treatment with orchiectomy. These comparative risks must incorporate a variety of data including GCT treatment efficacy, patient age, anesthesia risk, overall patient health/comorbidities, disease prevalence and the known increased risk of GCT in a UDT.

This clinical question was first analyzed by Martin and Menck in $1975 .{ }^{5}$ Using data from that time, they advised prophylactic orchiectomy in men only younger than the age of 50 as they determined that the risk of GCT death outweighed POM up to this age. For men older than 50, they recommended observation as POM began to outweigh the risk of GCT death.

As Martin and Menck used data from the 1940s-1960s to demonstrate mortality risk from GCT and calculate anesthesia risk, Farrer et al undertook an update of their study in 1985 which incorporated the dramatic improvements in survival from GCT around that time. ${ }^{6}$ Farrer et al identified a different prevalence for UDT in the general population, which ultimately changed the RR for developing GCT in men with UDT. ${ }^{6}$ The authors discovered the age at which the risk of death from prophylactic orchiectomy outweighs the risk of death from GCT is 32 years; thus, patients over 32 years old were not recommended to have surgery in their analysis.

The most recent analysis of this management dilemma is now over 15 years old. In their paper, Oh et al found that men who are healthy (American Society of Anesthesiologists (ASA) physical status class 1 or 2) should be advised to undergo orchiectomy, while those older than 50 should be advised to remain under observation. ${ }^{7}$ While these investigators thoroughly updated data on age-adjusted GCT risk and accounted for the notably improved POM risk since the last analysis, they utilized data on anesthesia POM risk dating from 1990 which was independent of surgical procedure risk.

As more contemporary studies on GCT mortality rates, POM risk and presence of GCT in UDT may change this recommendation, we looked to update these previous studies. The aim of our study was to provide a literature and statistically based guideline that patients and practitioners could use to help guide decision making in men presenting with a PP UDT.

\section{Methods}

To determine a clinical recommendation based on the age at presentation of a man with UDT, we compared the lifetime risk of GCT associated mortality based on age at presentation with the ASA class specific POM risk of orchiectomy. We compared respective risks to determine the age at which POM was lower than the GCT associated mortality. Below this determined age, 
orchiectomy would be preferred as the lifetime risk of GCT would be relatively higher, while observation would be preferred above this age.

Determining GCT mortality risk

The most recent data on GCT mortality in the U.S. were obtained from the National Center for Health Statistics. ${ }^{8}$ The lifetime risk of death from GCT in the male population was calculated for each 5-year interval. Standard life tables were used to calculate the cumulative risk over a man's lifetime based on the age at presentation with an UDT. The formulas for these standard life tables can be seen in the appendix.

The prevalence of non-pediatric UDT (over 18 years of age) was determined through a literature search. Papers defining UDT rates for men less than 18 years of age were not included. While rates of childhood and pediatric UDT are more common in the literature, this population was not our focus and reliable GCT mortality data is not available for this population. The defined prevalence of UDT in a reported 18-37 year old population served as the "expected" prevalence for future calculations. Alternatively stated, the "expected” prevalence is the likely prevalence if there were no relationship between UDT and GCT.

The increased risk of GCT in UDT is universally accepted in the urology community. However, the actual factor by which a UDT is at increased risk can be debated. We defined the "observed" prevalence through literature review of series of men identified as having GCT and the relative percentage of these men with UDT. Farrer et $\mathrm{al}^{6}$ performed a similar literature review for their publication and these studies were included in our contemporary update. More recent studies were identified utilizing a keyword based Pubmed search. Keyword terms for the search were "cryptorchidism, undescended testicle, germinoma, testis cancer". Search terms were meant to be overly inclusive to capture any possibly relevant study. Abstracts and full manuscripts were then reviewed to determine if they should be included. Data was then extracted from appropriate series and the studies were then weighted by number of patients in the overall cohort to calculate a weighted percentage of men with risk of developing GCT when they have UDT. These data and observed prevalence can be seen in Table 1.

Similar to the methods that Farrer et al originally utilized to calculate the RR of GCT for a patient with UDT, we divided the "observed" prevalence of GCT in UDT by the "expected" prevalence of UDT in the general male population. ${ }^{6}$ The age adjusted data on GCT in a man without UDT was then multiplied by this factor to obtain the RR of a male with UDT dying of germ cell malignancy.

Determining the risks associated with orchiectomy:

The POM for orchiectomy was defined through a determination of the inherent surgical risk associated with orchiectomy. As this is a straightforward urologic procedure that is relatively unstudied with regards to complications, there is no specific POM quoted in the literature. The 
procedure associated risk must therefore be extrapolated from comparative procedures and the POM of other procedures with a similar inherent risk.

We utilized the Cleveland Clinic cardiac risk stratification for non-cardiac surgery to determine the specific risk category for orchiectomy. ${ }^{9}$ This risk stratification used multivariate regression analysis to determine procedure-related mortality with procedures defined as low, intermediate or high risk. Low risk procedures include endoscopic procedures and procedures on superficial (non-intraperitoneal) structures. ${ }^{9}$ Based on these criteria we defined orchiectomy as a "low risk" procedure.

While procedures may be defined by their risk category, practitioners clearly realize that even low risk procedures in patients with significant co-morbidities are at a higher risk of POM. We therefore scoured the literature for surgical mortality predictors based on the ASA class. Glance et al created the Surgical Mortality Probability Model to guide clinical management for clinicians. ${ }^{10}$ This index defines the 30-day mortality risk index for non-cardiac surgery empirically derived from a retrospective cohort study of over 298,000 patients undergoing noncardiac operations. The mortality risk index is based on ASA physical status, emergency status and surgery risk class. This mortality risk was used to define the ASA class-specific POM risk in our paper.

\section{Results}

The literature review of studies looking at men with GCT to determine the "observed" prevalence can be seen in Table 1 . The weighted observed prevalence was found to be $7.02 \%$. While a variety of prevalence for UDT is quoted in the childhood/pediatric population, few studies have defined the prevalence of never before diagnosed UDT in men 18 years of age or older. The best study on this found an "expected" prevalence of 0.79\% amongst 10,000 men reporting for military duty. ${ }^{11}$

The RR of GCT in men with UDT relative to to those without UDT was estimated by dividing the probability of UDT in those with GCT (7.02\%) by the probability of UDT in the general population $(0.79 \%)$. This RR was found to be 8.89 .

The most recent age specific GCT was obtained from National Center for Health Statistics. ${ }^{8}$ Standard life tables were then calculated using the conventional formula as used by Oh et al. ${ }^{7}$ The lifetime risk of death from GCT in a patient with UDT in 5-year intervals was calculated by multiplying the computed risk value from standard life tables by 8.89 to determine the age-specific mortality of GCT from UDT (Table 2). This was then charted into Figure 1.

This lifetime risk was then formatted to a curve and the intercepts for $0.03 \%$ (mortality risk for ASA 1 ) and $0.08 \%$ (mortality risk for ASA 2) were determined. These intercepts were age 50.2 years for ASA 1 and 35.4 years for ASA 2. Men with an ASA class 3 or greater have a higher risk of POM compared to GCT for all ages; therefore they should never undergo orchiectomy as the mortality percentages for ASA 3 and 4 men are $0.49 \%$ and $3.31 \%$, respectively. ${ }^{10}$ 


\section{Discussion}

This paper updated the calculations on an important clinical question: how do we balance the GCT risks of previously untreated UDT in an adult with the POM of surgical treatment? As mentioned above, orchiectomy is a definitive solution for men with UDT and considering the minimal fertility contributions of these UDTs this is a reasonable option. We redefined the relevant ages at which the risks of POM and lifetime death from GCT intersect and now recommend that men under the age of 50.2 for health men (ASA class 1 ) and under the age of 35.4 for men with mild systemic disease (ASA class 2) consider prophylactic orchiectomy. Based on our calculations, men who are ASA class 3 or above should always undergo observation of a PP UDT due to their increased surgical risk.

Oh et al performed the most recent investigation in the management of the post-pubertal UDT now 15 years ago in 2002. Their analysis found that the risk of GCT associated death was greater than the risk of orchiectomy until the age of 50 years. ${ }^{7}$ While the approach utilized by Oh et al to calculate the lifetime risk from GCT is the same as the standard life table used in this study, the data used in their analysis is not applicable to patients today as it is from 1997 and does not incorporate advancements in care for men with GCT. Therefore, we obtained more contemporary data from the National Center for Health Statistics to update their analysis. ${ }^{8}$

The calculations used by Oh et al to calculate the RR of GCT in men with UDT are accurate and thoughtful but are not without assumptions that would be necessary for any paper taking this format. However, we attempted to use more data from the literature and less assumed entries. Since the RR is calculated by dividing the observed prevalence by the expected prevalence, we updated both aspects of this equation. To determine the observed prevalence, we performed a literature search and calculated a weighted value based on the number of patients in each study. This directly contrasts the methods of Oh et al, who used an unweighted average which would overvalue smaller studies and could be prone to sampling errors. We also obtained the actual prevalence of UDT in our ideal cohort of adults (age 18-37 years) from a large, widely accepted study, as opposed to using an estimation based on adolescent data. We redefined our $\mathrm{RR}$ as 8.89 which differs from the 9.7 used by Oh et al.

The authors of the previous analysis indirectly calculated the surgical risk for orchiectomy. Their analysis focused primarily on a study written in 1990 examining the effects of four different anesthetics on surgical mortality without regard to the inherent risk or type of procedure being performed and was not designed as a surgical risk predictor. ${ }^{12}$ From the results of this study, Oh et al extrapolated mortality rates for orchiectomy based solely on ASA risk status without the ability to incorporate the low risk categorization of orchiectomy due to the limitations in the literature at the time. Due to the interim work published by Glance et al, we were able to draw more specific POM numbers that are both surgical risk and ASA specific. 
The analysis of Glance et al in 2012 was a retrospective cohort study of 298,772 individuals undergoing noncardiac surgery from the American College of Surgeons National Surgical Quality Improvement Program (NSQIP) database. The goal of this 30-day surgical mortality probability model was to simplify shared decision making for surgeons and patients at the point of care and was intended to be a true "risk calculator". Glance et al included both ASA class and inherent surgical risk by category in their calculations. ${ }^{10}$ As Medicare has established 30 days as the cut-off for unplanned deaths after hospital care ${ }^{13}$, we believe a 30-day mortality index is a better measure of perioperative mortality than the 7 day timeframe that $\mathrm{Oh}$ et al were forced to use based on the available data at the time.

The UDT has a classically quoted prevalence of $2-4 \%$ at birth and $1 \%$ by $6-12$ months ${ }^{14}$ with spontaneous descent of the testis after one year of age considered infrequent. ${ }^{15}$ However, up to $40 \%$ of testes that descend in the first year may be found to later reascend into an abnormal position. ${ }^{14}$ With epidemiologic studies finding that $2-3 \%$ of boys undergo orchiopexy ${ }^{14}$ there is certainly some question about the classically quoted prevalence of $1 \%$ of 1 -year old boys having a UDT. While the actual prevalence of UDT in studies examining children and adults vary based on the selected study population and age ${ }^{16}$, the largest American study examined 10,000 military recruits between ages $18-37$ and found the prevalence to be $0.79 \%{ }^{11}$ In a large study looking a younger population than our desired adult population, Johnson ${ }^{17}$ found a prevalence of UDT of $1.7 \%$ in 31,609 boys aged 7-17 years. While the studies by Baumrucker ${ }^{11}$ and Johnson ${ }^{17}$ are certainly dated as they examined cohorts form the 1930s and 1940s, the most recent study reporting a rate of UDT in an American cohort was from $1993^{18}$. Unfortunately, data is from boys aged 1 year and found 1.1\% of the cohort having a UDT. While higher UDT rates were available and reported in the literature, we took $0.79 \%$ to be the most conservative (lowest) prevalence of a previously unrecognized UDT in a purely adult population.

While we believe our recommendations for prophylactic orchiectomy before ages 50.2 and 35.4 depending on patients' respective ASA class (1 or 2) are appropriately updated and revised for adults with UDT, these ages should serve as advisements for both clinicians and patients. In 2001, the Institute of Medicine published their landmark report Crossing the Quality Chasm in which they introduced the concept of shared decision making between patients and their physicians. ${ }^{19}$ They recommended that when patients and clinicians are faced with complex medical decisions there are a multitude of factors at play including patient values, preferences, clinician opinion and evidence-based guidelines regarding their condition. ${ }^{20}$ For these reasons our above recommendations should serve as an evidence-based advisement that should be considered as part of the discussion when an adult male presents with a previously unrecognized UDT.

Certainly, a study utilizing a variety of assumptions to answer a clinical question is not without limitations. The most glaring herein is the variety of assumptions needed to estimate the POM associated with orchiectomy. While this would be simplified by a well-defined cohort 
undergoing a prospective analysis of complications related to PP orchiectomy, this is not present in the current literature. While the absolute respective mortalities were the aim and ultimate outcome of this paper, morbidity associated both with observation and a subsequent diagnosis of GCT should be considered. The potential anxiety for men in an observation cohort could certainly affect quality of life along with an ongoing cost of observation instead of a definitive single treatment. In men later identified to have GCT, the morbidity of chemotherapy and radiation was not able to be incorporated into a study of this design but could potentially affect quality of life.

\section{Conclusion}

Previous evaluations in the management of men with post-pubertal UDT required updating. We found different ages at which observation is advised compared to the previous report. Thus, we advocate for prophylactic orchiectomy in men who are under 50 years if ASA class 1 and under 35 years if ASA class 2. Men with an ASA class 3 or higher should always undergo observation. 


\section{References}

1. Cooper, E.R.: The histology of the retained testis in the human subject at different ages and its comparison with the testis. J Anat, 64: 5, 1929.

2. Henderson, B. E., Ross, R. K., Pike, M. C., \& Depue, R. H. (1983). Epidemiology of testis cancer. Urological cancer. New York: Grune and Stratton, 237, 50.

3. Schottenfeld D., Warshauer, M. E., Sherlock, S., Zauber, A. G., Leder, M., \& Payne, R. (1980). The epidemiology of testicular cancer in young adults. American Journal of Epidemiology, 112(2), 232-246.

4. Giwercman, A., Grindsted, J., Hansen, B., Jensen, O. M., \& Skakkebaek, N. E. (1987).

Testicular cancer risk in boys with maldescended testis: a cohort study. The Journal of urology, 138(5), 1214-1216.

5. Martin, D. C., \& Menck, H. R. (1975). The undescended testis: management after puberty. The Journal of urology, 114(1), 77-79.

6. Farrer, J. H., Walker, A. H., \& Rajfer, J. (1985). Management of the postpubertal cryptorchid testis: a statistical review. The Journal of urology, 134(6), 1071-1076.

7. Oh, J., Landman, J., Evers, A., Yan, Y., \& Kibel, A. S. (2002). Management of the postpubertal patient with cryptorchidism: an updated analysis. The Journal of urology, 167(3), 1329-1333.

8. Centers for Disease Control and Prevention, National Center for Health Statistics. Underlying Cause of Death 1999-2015 on CDC WONDER Online Database, released December, 2016. Data are from the Multiple Cause of Death Files, 1999-2015, as compiled from data provided by the 57 vital statistics jurisdictions through the Vital Statistics Cooperative Program. Accessed at http://wonder.cdc.gov/ucd-icd10.html on Oct 20, 2016.

9. Fleisher, L. (2009). Cardiac risk stratification for noncardiac surgery. Cleveland Clinic journal of medicine, 76, S9.

10. Glance, L. G., Lustik, S. J., Hannan, E. L., Osler, T. M., Mukamel, D. B., Qian, F., \& Dick, A. W. (2012). The Surgical Mortality Probability Model: derivation and validation of a simple risk prediction rule for noncardiac surgery. Annals of surgery, 255(4), 696-702.

11. Baumrucker, G. O. (1946). Incidence of testicular pathology. Bulletin of the US Army

Medical Department. United States. Army. Medical Department, 5, 312.

12. Forrest, J. B., Cahalan, M. K., Rehder, K., Goldsmith, C. H., Levy, W. J., Strunin, L., ... \&

Domino, K. B. (1990). Multicenter study of general anesthesia. II. Results. Anesthesiology: The Journal of the American Society of Anesthesiologists, 72(2), 262-268.

13. Centers for Medicare and Medicaid Services. (2014). 30-day unplanned readmission and death measures. 
14. Barthold, J. S., \& González, R. (2003). The epidemiology of congenital cryptorchidism, testicular ascent and orchiopexy. The Journal of urology, 170(6), 2396-2401.

15. Cour-Palais, I. J.: Spontaneous descent of the testicle. Lancet, 1:1403, 1966

16. Sijstermans, K., Hack, W. W. M., Meijer, R. W., \& van der Voort-Doedens, L. M. (2008). The frequency of undescended testis from birth to adulthood: a review. International journal of andrology, 31(1), 1-11.

17. Johnson, W. W. Cryptorchidism. The Journal of the American Medical Association 1939; 113: 25-27

18. Berkowitz, G. S., Lapinski, R. H., Dolgin, S. E., Gazella, J. G., Bodian, C. A. \& Holzman, I. R. Prevalence and natural history of cryptorchidism. Pediatrics 1993; 92, 44-49.

19. Institute of Medicine. 2001. Crossing the Quality Chasm: A New Health System for the $21^{\text {st }}$ Century. Washington, DC: The National Academies Press. https://doi.org/10.17226/10027 20. Barry, M. J., \& Edgman-Levitan, S. (2012). Shared decision making - the pinnacle of patient-centered care. New England Journal of Medicine, 366(9), 780-781.

21. Batata, M. A., Chu, F. C., Hilaris, B. S., Whitmore, W. F., \& Golbey, R. B. (1982). Testicular cancer in cryptorchids. Cancer, 49(5), 1023-1030.

22. Debre, B., Gauthier, F., \& Steg, A. (1979). Cryptorchidism. Diagnosis and Treatment Pediat. adolesc. Endocr., Vol. 6, pp. 224-228

23. Forman, D., Pike, M. C., Davey, G., Dawson, S., Baker, K., Chilvers, C. E. D., ... \& Coupland, C. A. C. (1994). Aetiology of testicular cancer: association with congenital abnormalities, age at puberty, infertility, and exercise. Bmj, 308(6941), 1393-1399.

24. Gehring, G. G., Rodriguez, F. R., \& Woodhead, D. M. (1974). Malignant degeneration of cryptorchid testes following orchiopexy. The Journal of urology, 112(3), 354-356.

25. Herrinton, L. J., Zhao, W., \& Husson, G. (2003). Management of cryptorchism and risk of testicular cancer. American journal of epidemiology, 157(7), 602-605.

26. Kamat, M. R., \& Mehta, A. R. (1973). Testicular tumours associated with undescended testes. A retrospective study of 45 cases. Indian journal of Cancer, 10(1), 31.

27. Kuber, W. (1982). Testicular tumour and cryptorchidism. European urology, 8, 280-283. 28. Lanteri, V. J., Choudhury, M., Pontes, J. E., Wajsman, Z., Beckley, S., \& Murphy, G. P. (1982). Treatment of testicular tumours arising in patients with previous inguinal and/or scrotal surgery. The Journal of urology, 127(1), 58-59.

29. Miller, A., \& Seljelid, R. (1971). Histopathologic classification and natural history of malignant testis tumours in Norway, 1959-1963. Cancer, 28(4), 1054-1062.

30. Møller, H., Prener, A., \& Skakkebxk, N. E. (1996). Testicular cancer, cryptorchidism, inguinal hernia, testicular atrophy, and genital malformations: case-control studies in Denmark. Cancer Causes \& Control, 7(2), 264-274. 
31. Prener, A., Engholm, G., \& Jensen, O. M. (1996). Genital anomalies and risk for testicular cancer in Danish men. Epidemiology, 14-19.

32. Pugh, R. C. B.: Testicular tumours-introduction. In: Pathology of the Testis. Oxford: Blackwell Scientific, chapt. 4, p. 139, 1975.

33. Raina, V., Shukla, N. K., Gupta, N. P., Deo, S., \& Rath, G. K. (1995). Germ cell tumours in uncorrected cryptorchid testis at Institute Rotary Cancer Hospital, New Delhi. British journal of cancer, 71(2), 380.

34. Swerdlow, A. J., De Stavola, B. L., Swanwick, M. A., Mangtani, P., \& Maconochie, N. E. S. (1999). Risk factors for testicular cancer: a case-control study in twins. British Journal of Cancer, 80(7), 1098.

35. Swerdlow, A. J., Huttly, S. R., \& Smith, P. G. (1987). Testicular cancer and antecedent diseases. British journal of cancer, 55(1), 97.

36. Welvaart, K., \& Tijssen, J. G. P. (1981). Management of the undescended testis in relation to the development of cancer. Journal of surgical oncology, 17(3), 219-223.

37. Wobbes, T. H., Koops, H. S., \& Oldhoff, J. (1980). The relation between testicular tumours, undescended testes, and inguinal hernias. Journal of surgical oncology, 14(1), 45-51. 
Figures and Tables

Fig. 1. Lifetime risk of mortality from germ cell tumour (GCT) by age at presentation.

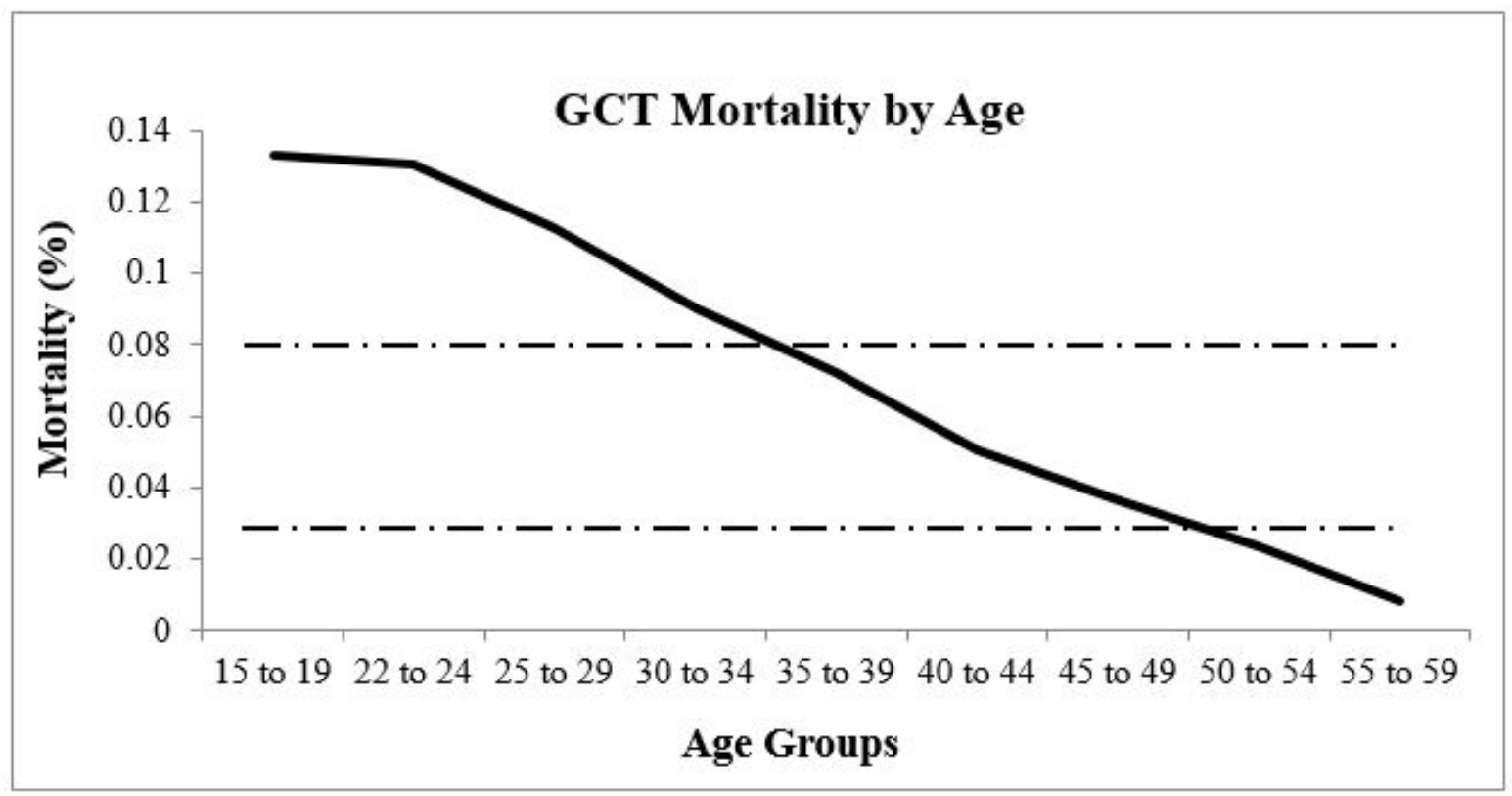




\begin{tabular}{|c|c|c|c|c|c|c|}
\hline Authors & $\begin{array}{l}\text { Total Cohort } \\
\text { with germ } \\
\text { cell tumour }\end{array}$ & $\begin{array}{c}\text { Number } \\
\text { with UDT }\end{array}$ & Weight & Fraction & Percentage & $\begin{array}{c}\text { Weighted } \\
\text { percentage }\end{array}$ \\
\hline 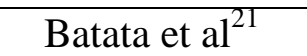 & 1000 & 125 & 0.1 & 0.13 & 12.5 & 1.3 \\
\hline Debre et $\mathrm{al}^{22}$ & 80 & 14 & 0.01 & 0.18 & 17.5 & 0.15 \\
\hline Forman et $\mathrm{al}^{23}$ & 794 & 65 & 0.08 & 0.08 & 8.19 & 0.68 \\
\hline Gehring et $\mathrm{al}^{24}$ & 529 & 37 & 0.06 & 0.07 & 6.99 & 0.39 \\
\hline Herrinton et $\mathrm{al}^{25}$ & 183 & 12 & 0.02 & 0.07 & 6.56 & 0.13 \\
\hline 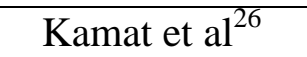 & 380 & 45 & 0.04 & 0.12 & 11.84 & 0.47 \\
\hline Kuber et $\mathrm{al}^{27}$ & 990 & 71 & 0.1 & 0.07 & 7.17 & 0.74 \\
\hline${\text { Lanteri et } \mathrm{al}^{28}}^{28}$ & 300 & 13 & 0.03 & 0.04 & 4.33 & 0.14 \\
\hline Miller et $\mathrm{al}^{29}$ & 314 & 25 & 0.03 & 0.08 & 7.96 & 0.26 \\
\hline Moller et $\mathrm{al}^{30}$ & 830 & 7 & 0.09 & 0.01 & 0.84 & 0.07 \\
\hline Prener et $\mathrm{al}^{31}$ & 183 & 16 & 0.02 & 0.09 & 8.74 & 0.17 \\
\hline Pugh et $\mathrm{al}^{32}$ & 2448 & 123 & 0.26 & 0.05 & 5.02 & 1.28 \\
\hline Raina et al ${ }^{33}$ & 164 & 24 & 0.02 & 0.15 & 14.63 & 0.25 \\
\hline 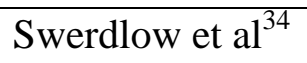 & 194 & 7 & 0.02 & 0.04 & 3.61 & 0.07 \\
\hline Swerdlow et al ${ }^{35}$ & 259 & 27 & 0.03 & 0.1 & 10.42 & 0.28 \\
\hline${\text { Welvaart et } \mathrm{al}^{36}}^{36}$ & 717 & 51 & 0.07 & 0.07 & 7.11 & 0.53 \\
\hline Wobbes et $\mathrm{al}^{37}$ & 230 & 12 & 0.02 & 0.05 & 5.22 & 0.13 \\
\hline Total & 9595 & 674 & 1.00 & $\overline{\mathrm{n} / \mathrm{a}}$ & 8.16 & 7.02 \\
\hline
\end{tabular}

GCT: germ cell tumour; UDT: undescended testicle. 
Table 2. Lifetime risk of GCT mortality in patients

\begin{tabular}{|c|c|c|c|}
\hline Age & Mortality rate & \% lifetime risk & $\begin{array}{c}\text { \% lifetime risk with } \\
\text { UDT }^{*}\end{array}$ \\
\hline $15-19$ & 0.0649 & 0.0150 & 0.1331 \\
\hline $20-24$ & 0.4004 & 0.0146 & 0.1302 \\
\hline $25-29$ & 0.5017 & 0.0126 & 0.1124 \\
\hline $30-34$ & 0.3978 & 0.0101 & 0.0901 \\
\hline $35-39$ & 0.4930 & 0.0081 & 0.0724 \\
\hline $40-44$ & 0.3131 & 0.0057 & 0.0505 \\
\hline $45-49$ & 0.2988 & 0.0041 & 0.0366 \\
\hline $50-54$ & 0.3430 & 0.0026 & 0.0233 \\
\hline $55-59$ & 0.1819 & 0.0009 & 0.0081 \\
\hline
\end{tabular}

*Lifetime risk x 8.89. GCT: germ cell tumour; UDT: undescended testicle. 


\section{Standard life table calculation ${ }^{*}$}

1. ${ }_{\mathrm{a}} \mathrm{M} \cdot \mathrm{x}$, the germ cell tumour mortality rate for men between the ages $\mathrm{x}$ to $\mathrm{x}+\mathrm{a}$

2. $\mathrm{a}_{\mathrm{x}}$ the germ cell tumour mortality probability during the interval $\mathrm{x}$ to $\mathrm{x}+\mathrm{a}$ in those alive at age $x$

3. ${ }_{a} P_{x}$, the germ cell tumour survival probability during the interval $x$ to $x+a$ in those alive at age $x$

4. $S_{x}$, the overall probability of not dying from germ cell tumour during lifetime in those alive at age $\mathrm{x}$

5. $\mathrm{LR}_{\mathrm{x}}$, the lifetime risk of dying from germ cell tumour (probability of GCT mortality during lifetime) of those alive at age $\mathrm{x}$

Thus,

${ }_{\mathrm{a}} \mathrm{Q}_{\mathrm{x}}=\mathrm{a} *{ }_{\mathrm{a}} \mathrm{M}_{\mathrm{x}} /\left(1+0.5 * \mathrm{a} *{ }_{\mathrm{a}} \mathrm{M}_{\mathrm{x}}\right)$

${ }_{\mathrm{a}} \mathrm{P}_{\mathrm{x}}=1-{ }_{\mathrm{a}} \mathrm{Q}_{\mathrm{x}}$

Using 5 year intervals up to age 60:

$\mathrm{S}_{\mathrm{x}}={ }_{5} \mathrm{P}_{\mathrm{x}} *{ }_{5} \mathrm{P}_{\mathrm{x}+5} * \ldots *{ }_{5} \mathrm{P}_{60}$

The lifetime risk for those alive at age $\mathrm{x}$ is $\mathrm{LR}_{\mathrm{x}}=1-\mathrm{S}_{\mathrm{x}}$.

${ }^{*}$ As demonstrated in Oh et $\mathrm{al}^{7}$ 